\title{
Iglesia Católica y modernidad contemporánea: una mirada desde Latinoamérica
}

\author{
Aldo Rubén Ameigeiras*
}

\section{Resumen}

El presente artículo aborda la situación de la Iglesia católica frente a la gravedad de la crisis que atraviesa en la actualidad y que pone en discusión su posicionamiento ante la complejidad de la sociedad y las particularidades de las modernidades múltiples que la caracterizan. Una Iglesia católica que a través del tiempo ha llevado a cabo giros y reposicionamientos tendientes a definir su adecuación, resistencia o enfrentamiento ante los cambios por los que ha atravesado la sociedad y que se encuentra en este momento en los inicios de un nuevo pontificado. Interrogantes que se renuevan y nuevos desafíos que se presentan ante una diversidad de problemáticas y demandas en el marco de esta modernidad contemporánea.

Palavras clave: Iglesia católica; modernidad contemporánea; crisis de la Iglesia; el Papa Francisco.

\section{Catholic Church and Contemporary Modernity: a Look from Latin America}

\section{Abstract}

This article deals with the catholic church situation in front of the gravity crisis that it is going through nowadays, which one puts on discussion its place in front of the complexity of the society and the peculiarities of the multiples modernities which characterize it. One catholic church that through the years has carried through changes of direction and news positions that tends to define its adaptation, resistance or confrontation to the changes that the society has experienced, and which is at this moment at the beginning of a new pontificate. Renewed Questions and new challenges that come in front of a diversity of problematic and demands in the setting of this contemporary modernity. Keywords: Catholic Church; Contemporary modernity; Crisis of the church; Francisco Pope

Los comienzos del siglo XXI han encontrado sociedades insertas en profundas transformaciones socio-económicas políticas y culturales en una globalización marcadamente asimétrica con el predominio de políticas neoliberales. Una humanidad que se debate entre la persistencia de situaciones

* Sociólogo, Investigador, docente no Instituto del Desarrollo Humano - Universidad Nacional de Gral Sarmiento - CONICET. E-mail: aameigei@ungs.edu.ar . 
de pobreza, desigualdad y violencia por un lado y la mayor conciencia de la necesidad de reafirmar los derechos de las minorías y el respeto y la vigencia de los DDHH por el otro. Un mundo en donde las transformaciones científicas y tecnológicas ,los cambios en los medios de comunicación, la presencia de Internet y la emergencia de las redes sociales a la vez que han contribuído a una mayor comunicación han transformado los universos simbólicos y gravitado en el imaginario colectivo.

Cambios en general en el marco de la modernidad contemporánea que han incidido profundamente en la trama socio-cultural de la sociedad y que entre otros aspectos han gravitado en las creencias y prácticas religiosas en donde no solo nos encontramos ante la persistencia de tradiciones religiosas sino también ante la emergencia de nuevos movimientos, de una diversidad de modalidades del creer, como de distintas formas de no-creencia e indiferentismo religioso. Sociedades en donde las singularidades del proceso de secularización con una marcada desregulación de las creencias y el acrecentamiento de los procesos de individuación y autonomización no solo ha permitido una mayor visibilidad de formas de religiosidad y cultos populares sino que a la vez ha acrecentado la crisis y los desafíos de las instituciones religiosas. Instituciones por otro lado insertas en contextos cambiantes, caracterizados no solo por un marcado pluralismo religioso sino por "fronteras móviles" y "conflictos interculturales". ${ }^{1}$

En dicho contexto la Iglesia Católica aparece como una institución en donde observar la gravitación de las transformaciones ocurridas y las características de las crisis que afectan a las instituciones religiosas. Una instancia que alcanza una relevancia especial dada la importancia institucional que posee la Iglesia y a la vez la magnitud de la crisis que la atraviesa. Una institución que no solo representa a más de 1000 millones de creyentes en el mundo sino que a su vez posee la peculiaridad de conformar un Estado, con sus correspondientes autoridades, embajadores en las distintas naciones, presupuesto, banco y organización jurídica y administrativa. Una Iglesia que tuvo un enfrentamiento fundamental con la modernidad en sus inicios y que luego transitó por distintos momentos de encerramiento como de oposición , de despliegue de estrategias institucionales defensivas a otras de clara ofensiva e intervención ,en síntesis de mayor o menor apertura en sus relaciones con la sociedad y los Estados. Un posicionamiento que desde un fuerte abroquelamiento teológico y doctrinario con múltiples consecuencias pastorales e implicancias sociales y políticas pasó a otros posicionamientos de mayor amplitud y diálogo. Una Iglesia Católica que se enfrenta hoy ante la realidad de "modernizaciones y secularizaciones múltiples" entre las cuales emerge la singularidad de la modernidad Latinoamericana.

1 C Parker (2011) Cambio religioso, fronteras móviles e interculturalidad - Pag. 17 en A.

Higuera Bonfil ( coord.) Religión y Culturas contemporáneas-Edit. Manda - México 
Una Iglesia Católica que no solo se encuentra en la actualidad ante la ruptura de su monopolio religioso en Latinoamérica (que ejerció durante siglos practicando una política de instauración de la unanimidad religiosa) y la consolidación del pluralismo religioso sino a su vez ante la escasez de sacerdotes y la paulatina pero permanente disminución de católicos. Una situación de crisis en cuyo marco se produce la renuncia al Papado de Benedicto XVI y la elección de un cardenal Latinoamericano, J. Bergoglio, como el Papa Francisco. Una renuncia y una elección que ha abierto la puerta a múltiples análisis y reflexiones en donde las apreciaciones, más allá de aquellas encuadradas institucionalmente que celebran la llegada del nuevo Papa, transitan entre perspectivas escépticas o esperanzadas. Consideraciones que teniendo en cuenta los antecedentes del actual Papa, sostienen que se " trata más de lo mismo" en cuanto la elección constituye fundamentalmente una instancia de readecuación que sin embargo no cambiará la tendencia conservadora predominante en la institución. Pero por otro lado apreciaciones esperanzadas no solo como consecuencia de su procedencia Latinoamericana sino especialmente como resultado del impacto producido por los primeros gestos y signos que han acompañado su asunción del papado. Surgen así interrogantes de distinta índole:¿Nos encontramos ante una situación de crisis especial de la Iglesia Católica en contexto de la modernidad? ¿Es factible esperar un nuevo cambio o readecuación institucional ante las nuevas circunstancias? ¿La gravedad de las denuncias y escándolos que han trascendido pública y mediáticamente encontrarán una respuesta adecuada? ¿Los insistentes reclamos internos seguirán postergados o finalmente encontrarán una respuesta? ¿Cuales serán los planteos del nuevo Papa ante este cuadro de situación ? Diversidad de preguntas que nos permiten considerar que más allá de las continuidades o las rupturas, de las transformaciones profundas o superficiales de las pujas teológicas y pastorales, lo que ocurra ha de gravitar decididamente no solo en el campo religioso sino a su vez y fundamentalmente a nivel socio político como cultural en nuestro continente. Perspectivas que nos llevan a sostener, a manera de hipótesis de trabajo, que la Iglesia Católica, si bien es lenta para responder a los cambios que se van produciendo en la sociedad, posee una marcada capacidad de respuesta a los mismos afirmando o replanteando estrategias institucionales, de adecuación, acompañamiento, resistencia o enfrentamiento, acorde a las circunstancias y en el marco de sus ejes teológicos y doctrinarios. De esta forma, dichas estrategias más que constituirse en excepcionalidades conforman generalmente giros de readecuación que habilitan el reposicionamiento de corrientes y perspectivas del catolicismo predominantes hasta ese momento o por otro lado otorgan viabilidad a aquellas otras corrientes que estaban postergadas o habían sido claramente desplazadas de la estructura del propio poder eclesiástico. 
En el presente trabajo nos interesa reflexionar precisamente en las características e implicancias de estos procesos, sosteniendo que la forma en que se resuelvan serán importantes no solo en relación a los comportamientos institucionales de las religiones en las próximas décadas sino también y fundamentalmente para los procesos de consolidación democrática y de amplitud de derechos en Latinoamérica. De esta forma abordaremos tres instancias que consideramos fundamentales. En primer lugar respecto a la Iglesia Católica en relación a la modernidad en general y a las modernidades en particular, considerando especialmente la situación Latinoamericana.

En segundo lugar abordaremos las singularidades de la crisis actual que atraviesa la Iglesia católica y finalmente la nueva situación planteada a partir del acceso a la conducción de la Iglesia por el papa Francisco..

\section{Modernidad y modernidades; Giros, posicionamientos y estrategias de la Iglesia Católica}

El despliegue de la llamada modernidad en Europa implicó una serie de transformaciones en la sociedad que especialmente desde el siglo XVII y XVIII se explicitaron en distintos procesos sociales, económicos, políticos y culturales de enormes consecuencias, no solo en Europa sino también posteriormente en el resto del mundo. Así la Revolución Francesa y sus consecuencias como las revoluciones industrial y científica-tecnológica se explicitaron en movimientos de "emancipación, expansión, renovación y democratización" que indudablemente produjeron un cambio radical en el cual la llamada "razón moderna" pasó a constituirse en el eje vertebrador de la vida social. El proceso de racionalización tuvo así consecuencias en la cosmovisión como en los hábitos de los ciudadanos y las formas de organización social vigentes hasta ese momento. Una perspectiva que implicó una concepción de la autonomía del hombre y de la libertad a la vez que de clara diferenciación de esferas en lo social. Distintos autores han hecho mención y han debatido acerca de los diversos momentos por los que ha transitado esta modernidad que incluso para algunos determina lo que hoy es denominado, también conflictivamente, como posmodernidad. ${ }^{3}$ Una diversidad de situaciones que a su vez requieren tener en cuenta que estamos ante distintas manifestaciones históricas de la modernidad. No se trata entonces de hacer

\footnotetext{
2 N. Garcia Canclini(2001) “Culturas híbridas”-Estrategias para entrar y salir de la modernidad- pag. 51-Paidos-Bs. As.

3 Son numerosos los trabajos y autores sobre la temática. Mencionamos en particular el trabajo compilado por N. Casullo sobre “ El debate modernidad pos modernidad-(1993) El cielo por asalto- Bs As-en el que participan autores como J. Habermas,M.Berman ,J.Lyotard,P. Anderson o P. Burger en tre otros./
} 
mención a "la modernidad" en cuanto alusión a la existencia de una modernidad en particular sino a "modernidades múltiples". 4

A esta altura de la reflexión resulta importante recordar a su vez en esa línea que el despliegue de la denominada modernidad implicó el tránsito por distintos momentos históricos, desde perspectivas amplias y emancipadoras a otras más restringidas y absolutizadoras que involucraban el predominio de una "racionalidad instrumental" en el marco de una "lógica totalizadora" que desconocía la existencia de "otras racionalidades y otras lógicas." Un proceso que ha llevado a una profunda revisión crítica de la noción de modernidad desde los pueblos que sufrieron los embates del colonialismo y sus planteos excluyentes en nombre de una supuesta racionalidad universal. Una situación en donde el "fin del mito del progreso indefinido" no solo dejó al descubierto las limitaciones y vulnerabilidad del "proyecto moderno" sino que también implicó considerar la existencia de "otras lógicas” y demandó la construcción de nuevos planteos epistemológicos. ${ }^{5}$

Realizar este abordaje de la modernidad resulta fundamental en cuanto es en relación con la misma que resulta necesario analizar la situación actual de la Iglesia Católica considerando especialmente que dicha relación con la modernidad se ha constituído en un núcleo central de la disputas, tensiones y conflictos que la Iglesia católica ha desarrollado con la sociedad y los estados especialmente desde los finales del siglo XIX hasta la actualidad. Su posicionamiento ante la modernidad ha sido clave desde un primer momento en cuanto implicó no solo un distanciamiento sino un enfrentamiento que se profundizó en los años posteriores. Una situación que transitó desde momentos de encerramiento, hasta otros de mayor apertura y posibilidades de diálogo. Una situación que permite observar la presencia de estrategias institucionales que de alguna manera se posicionan frente a los cambios sociales, políticos y culturales como frente a las situaciones de crisis. Así la perspectiva intransigente de Pio IX en relación la modernidad marcó un hito fundamental con la aparición en 1867 de su famoso" Syllabus errorum "en donde plantea los errores y condenaba la cultura del mundo moderno. El pontificado del León XIII, implicó una nueva estrategia de intervención en la sociedad y de preocupación por lo social con su encíclica Rerum

4 M.C. Reigadas : Modernidades múltiples e historia globlal- Inst. G. Germani - Fac. C. Sociales. -UBA- pag. 6- La autora señala los orígenes de la formulación de las teoría de las modernidades múltiples realizada por S. Eisesnstdt

5 Cfr. E. Lander (2000) La colonialidad del saber:Eurocentrismo y ciencias sociales .Perspectivas Latinoamericanas- Clacso -Bs.As/ Boaventura de Souza Santos ( 2009)-Una Epistemología del sur: La reinvención del conocimiento y la emancipoación social- Siglo XXI-Clacso- Bs. As. "-ver también J.C. Scannone (19919 "Nueva modernidad adveniente y cultura emergente"-Pag. 148- Stromata .-Bs. As 
Novarum", si bien Leon XIII dió continuidad a los postulados doctrinarios planteados por sus antecesores en cuanto a su apreciación sobre la modernidad, como señala $G$. Farrell ${ }^{7}$

"El papel que cumple León XIII es definir el hecho de que la Iglesia estaba frente a una sociedad nueva una verdadera herejía hecha cultura y organización social cuyo origen estaba en la ruptura de la cristiandad del siglo XVI".

Sin embargo la agudización de la crisis social es la que motiva el surgimiento de una nueva estrategia institucional a través del despliegue de una fuerte actividad institucional y pastoral en la que se plantea el objetivo de poner en marcha la " evangelización del mundo moderno" y la toma de posición ante la problemática social aparecida con la revolución industrial. En ese marco es fuerte su preocupación por las características de la relación entre el Estado y la religión. Una situación esta ultima que aparece de hecho en varias encíclicas sobre este tema ${ }^{8}$. Resulta importante en este punto señalar que el planteo de "evangelización del mundo moderno" constituye una finalidad en las opciones pastorales tendiente a consolidar y multiplicar los planteos tanto de "inculturación" como de "catolización" de la sociedad y la cultura dando lugar a partir de dicho momento a una variedad de propuestas pastorales y formas de intervención social .A partir del Pontificado de León XIII sus sucesores darán continuidad a sus preocupaciones sociales como también a sus afirmaciones en torno de la sociedad moderna y especialmente a los nuevos posicionamientos de los Estados. Si León XIII con su Encíclica "Rerum Novarum " inició prácticamente lo que se conoce como la "Doctrina social de la Iglesia“"sus sucesores en lo inmediato ,Pío XI, como Pío XII continuarán con dicha estrategia posicionándose en temas como las relaciones con la política ,las reformas del Estado, o la economía y manteniendo las condenas al ateísmo, el liberalismo,el capitalismo como el socialismo y el comunismo. Planteos en donde aparecen muchos temas, desde la condena al " laicismo social" con Pio XI hasta la reinvindicación de parte de la Iglesia Católica de su " derecho a intervenir en la vida publica "con Pío XII. ' .Sin embargo a partir de Juan XXIII se abre una nueva línea especialmente con la convocatoria al Concilio Vaticano II en 1962. Ante un momento de profundos cambios, en el marco de una década del sesenta movida por acontecimientos de fuertes transformaciones culturales, políticas y sociales como de movimientos de demandas de libertad y la creatividad, se produce un nuevo giro. Esta vez predomina la

\footnotetext{
$6 \quad$ Enc. Rerum Novarum - Edic. BAC

7 G. Farrell (1983)Doctrina social de la Iglesia .- Introduccion e historia de los doc. sociales pontificios y del Episcop. Latinoamericano y argentino- Edit. Guadalupe- pag. 58 cfr al respecto, Quod Apostolici Muneris (1878) Inmortale Dei (1885)

G. Farrell - op. Cit. Pag. 95
} 
apertura como vertebradora de los planteos episcopales. Un acontecimiento de gran repercución en donde se destacan los documentos " Gaudium et Spes "y "Lumen gentium" que implicaron de hecho una instancia clave de diálogo con la modernidad y de búsqueda de respuestas ante las nuevas problemáticas y expectativas de la humanidad. Una situación ésta última cuyo impacto marcó profundamente a la Iglesia católica en general en los mediados del siglo XX y que conmovió muy especialmente a la Iglesia Católica de Latinoamérica. De esta manera se abrió luego de un período de encerramiento y ortodoxia doctrinaria un período de apertura y cambio que no solo acompañó la magnitud de las transformaciones que caracterizaron la década del sesenta sino que también posibilitó un diálogo abierto con dichos cambios en el marco de "Modernidades Latinoamericanas" fuertemente atravesadas por demandas de todo tipo. El Pontificado de Paulo VI, además de llevar adelante el Concilio Vaticano II produce entre otros documentos su Encíclica "Populorum Progressio"(1967) que tendrá a su vez una enorme significación para América Latina y los pobres en particular.$^{10}$ Posteriormente la Conferencia episcopal de Medellín (1968) constituye una muestra acabada de la necesidad de encarnar en cada lugar y cada cultura la renovación conciliar, tanto como por su denuncia de la situaciones de injusticia existente en Latinoamérica como por su compromiso con los pobres y excluídos que marcaba una manera distinta de ser Iglesia en Latinoamérica. Un momento en que la Teología de la Liberación permitió desarrollar una conciencia y una mirada amplia que nutrió la reflexión y la acción de los católicos comprometidos con la construcción de una sociedad más justa en todo el continente.

Sin embargo, no tardó demasiado tiempo en trastocarse la situación. Paulatinamente los cambios producidos en la situación mundial en la década del 80, con el desmembramiento de la Unión Soviética y la caída del muro de Berlin con el nuevo realineamiento del poder mundial, pasando por el auge del neoliberalismo y en el caso Latinoamericano el despliegue de dictaduras militares, llevaron a un nuevo giro institucional en el que las corrientes conservadoras se reposicionaron nuevamente y la fuerza de un conservadorismo neoliberal tuvo su correlato institucional en el seno de la Iglesias Católica. Un posicionamiento que retoma su enfrentamiento con la modernidad y genera un nuevo momento de encerramiento institucional. Así de posiciones progresistas y de renovación se pasa nuevamente a una posición conservadora y ortodoxa con una gran realineamiento institucional conducido por Juan Pablo II. Sin embargo no terminaba allí la problemática

10 G. Gutierrez (1997) “Desarrollo nuevo nombre de la paz:A los treinta años de la Populorum progressio”- pp. 445-457- en R.Ferrara-C-.Galli -Presente y futuro de la teología en la Argentina-Hoenaje aL. Gera- Edic. Paulinas 
sino que en el marco de la misma institución comenzaron a aparecer signos importantes que aludían a que la crisis estaba presente y que su relevancia se iba incrementando cada vez más.

\section{II : De una crisis profunda a la profundidad de la crisis}

En la breve recorrida que hemos realizado en los párrafos anteriores hemos hecho una reiterada alusión a la presencia de crisis. En algunos de los momentos y situaciones que han acompañado el desarrollo de la institución con un largo recorrido histórico. Como señaló E. Poulat refiriéndose a la Iglesia, "Su historia es una sucesión de crisis" 11 . De allí también la enorme cantidad de artículos, estudios y encuentros de reflexión vinculados con la crisis de la religión y de la Iglesia, especialmente en los fines del siglo XX y comienzos del tercer milenio. ${ }^{12}$ Es que como señala R. Blancarte " Las crisis nunca han sido extrañas a las religiones". ${ }^{13}$ Crisis como momentos especiales en que las situaciones normales de conflicto no solo se acrecientan sino que alcanzan una virulencia especial. Situaciones que demandan reposicionamientos que pueden derivar en cambios de carácter coyuntural o por el contrario en transformaciones que marquen un nuevo rumbo institucional. Al respecto es importante diferenciar estas situaciones de crisis de las situaciones de conflictos en cuanto estos últimos no solo son constitutivos de lo social sino que acompañan permanentemente la vida de la instituciones. Si bien en muchas oportunidades se suelen encubrir las crisis abordándolas y definiéndolas exclusivamente como conflictos vinculados con problemas específicos. Una distinción que resulta importante realizar en la Iglesia Católica en cuanto conviven hoy en la misma una diversidad de conflictos, algunos más urgentes de resolución que otros, pero sobre el marco de una crisis profunda que se ha ido incrementando en su importancia en los últimos años. Una crisis que exterioriza, para muchos creyentes, el agotamiento de un modelo de Iglesia y la necesidad de construir una nueva manera de ser Iglesia .Una crisis que algunos definen como irreversible y otros como coyuntural pero que ineludiblemente requiere de una respuesta institucional impostergable ${ }^{14}$

11 Emile Poulat (1996) Oú va le christianisme?- Plon/Mame-France

12 Ameigeiras A,N.Boulgourdjan,F.Mallimaci,J.Soneira(orgs)(2002) II Jornadas de Ciencias sociales y Religión - "La religión en tiempos de crisis "“- CEIL-Bs. As.

13 Roberto Blancarte - "Libertades religiosas y libertades civiles en tiempo de crisis"-- en A.Ameigeiras et all(orgs) op.cit Pag.7.

14 Cfr P. Richard (2005) Crisis irreversible en al Iglesia Católica pero otra manera de ser Iglesia también es posible “- Pasos- No. 118- PAG. 2- Ver también Antonio Fidalgo . Teología Latinoamericana;Temas irrenunciables y pendientes a partir del Congreso Continental de Teología- pag. 13- Congreso Continental de Teología-revista CLAR- Año L - No. 4- Octubre diciembre- 2012 
Una crisis que es abordada en forma distinta según las diversas corrientes y catolicismos y en donde aparecen una diversidad de problemáticas; Desde aquellas vinculadas con las transformaciones de lo religioso en la sociedad actual y las características del proceso de secularización, pasando por las demandas por una democratización de la Iglesia(tanto a nivel del reclamo de colegialidad como de replantear la forma de elección de los Obispos)o los reclamos por el acceso al sacerdocio de la mujer o la existencia de un celibato opcional .Una modernidad que supone no solo el desafío del reconocimiento sino básicamente de la asunción de la singularidad cultural de Latinoamérica que gravita tanto en las peculiaridades de la secularización como en las características de la laicidad. Una situación que acrecienta la relevancia de la pluralidad cultural como una instancia clave a considerar en el abordaje de las problemáticas de lo religioso en las sociedades Latinoamericanas en la actualidad. Un hecho que coloca en un lugar fundamental la necesidad del despliegue de una perspectiva intercultural que permita despegarse de monoculturalismos y posicionamientos tanto filosóficos como teológicos anclados en un eurocentrismo persistente .Al respecto señala Cristian Parker

"Hay que comprender las transformaciones de lo religioso en el marco de los procesos interculturales del presente y en e contexto de las condiciones de emergencia de redefiniciones históricas del propio fenómeno religioso,lo que nos obliga a repensar en lo que clásicamente estamos entendiendo por centro y por márgenes en la propia naturaleza del fenómeno religioso" ${ }^{15}$

Una afirmación desde la cual avanza en considerar la necesidad de desplegar una perspectiva intercultural dinámica que "destaque los puntos de conflicto ,negociación y construcción, en nuevas fases de síntesis culturales". ${ }^{16}$ En este punto resulta fundamental lo señalado por Raul Fornet Betancourt ${ }^{17}$, quien hace alusión al tipo de cristianismo que se ha insertado y expandido en América. Un cristianismo que en realidad conforma una " configuración occidental del cristianismo", un "cristianismo culturalmente determinado". Esto no implica desconocer que la forma que adquirió el cristianismo occidental - europeo haya sido la más adecuada para dicho contexto socio cultural, pero que claramente el cristianismo que se ha desarrollado en estas tierras no ha asumido plenamente las singularidades de la trama socio cultural y las matrices culturales de los pueblos latinoamericanos y en tal sentido ha

15 Cristián Parker G- (2011) Una visión sobre América latina- Cambios religiosos, fronteras móviles e interculturalidad-pag. 16--La Editorial manda- México -

16 Cristian Parker-op.cit-Pag.24

17 R, Fornet Betancourt (2007) Interculturalidad y religión -pag. 12- Edic. Abya Yala- Ecuad 
generado instancias de imposición más que de asunción de la cultura. Se trata del desafío de construir un "cristianismo desoccidentalizado", apreciación en la que coincide con Parker y que de hecho acrecienta la necesidad del descubrimiento y despliegue de una dinámica intercultural que posibilite la recuperación de la fecundidad de los universos simbólicos y las particularidades de estas culturas. "Lo radical de esta perspectiva no es pues que tengamos que contar con un cristianismo policéntrico, sino con un cristianismo culturalmente plural". ${ }^{18}$

Por otro lado nos enfrentamos al desafío de construir una laicidad que a la vez que asegure el pluralismo religioso en condiciones de libertad e igualdad contribuya a los procesos de ampliación de derechos y de consolidación de las democracias en Latinoamérica. La relación de las Iglesia con los Estados pone sobre la mesa el desafio de construcción de la laicidad considerada un elemento clave en la consolidación de los procesos democráticos. Una Laicidad que asume diversos modos de explicitación acorde a la singularidad de los procesos históricos y políticos de cada nación pero que conforma una instancia clave de garantizar tanto la libertad de conciencia y de religión como " el derecho a su práctica individual y colectiva" sobre la base de la autonomía de lo político y de la sociedad civil de todo tipo de creencia o norma religiosa particular. ${ }^{19}$ Pero una laicidad que en cada nación asume singularidades propias y que requiere permanentemente ser construída y ser perfeccionada. Una laicidad entendida como señala R. Blancarte ${ }^{20}$

"Como un régimen social de convivencia,cuyas instituciones políticas están legitimadas principalmente por la soberanía popular y ya no por elementos religiosos".

Una situación que no excluye que las relaciones entre lo político y lo religioso sean fluídas y que se presenten distintas instancias de diálogo y articulación como también de intersecciones y cruces.

\section{Nuevo giro o vieja estrategia; Entre la certeza y la incertidumbre}

Hemos hecho alusión al comienzo de nuestro trabajo a distintos momentos históricos por los que ha transitado la Iglesia Católica en su relación con la modernidad. En los mismos aparece claramente la existencia de giros y cambios en las estrategias institucionales que implican reposicionamientos

\footnotetext{
18 R. Fornet Betancourt -op.cit-pag.29

19 F. Mallimaci (2006) - - Religión , política y Laicidad en la Argentina del siglo XXI-pag.78 en Nuda Costa (org) Laicidad en América Latina y Europa- Claeh- Alfa

20 R. Blancarte - Laicidad, la construcción de un concepto de valides universal -pag. 46 en N.Da Costa (org) Laicidad en América Latina y Europa- Claeh- Alfa
} 
frente a las transformaciones sociales como a las crisis institucionales. Los finales del siglo XX y comienzos del tercer milenio explicitaron abiertamente la presencia de una diversidad de hechos y transformaciones sociales a las que se enfrentó Juan Pablo II en su extenso pontificado. Una situación que requeriría un análisis minucioso que no podemos realizar en esta oportunidad lo cual no impide que hagamos alusión a algunas de las grandes líneas que caracterizaron el mismo. De esta manera debemos destacar tanto la relevancia de su carisma personal y su propuesta de comunicación directa con las grandes mayorías de creyentes en el mundo, como la profundidad del giro institucional que llevó a cabo .En el primer caso en cuanto su "peregrinar" por los más diversos países le permitió recuperar el fervor colectivo de las multitudes catòlicas que lo reconoció como un líder de envergadura mundial, en la segunda instancia en cuanto dicha apertura fue contrarrestada con un reposicionamiento conservador y doctrinariamente ortodoxo acompañado por una política de centralización y fortalecimiento de la autoridad papal. El replanteo realizado no solo alcanzó aspectos pastorales y teológicos (incluso con el desplazamiento y la condena de otras teologías católicas como pasó con la teología de la liberación)sino que llevó a cabo modificaciones institucionales ,tanto interna como externa de relevancia. Avanzó internamente en el nombramiento de cuadros eclesiásticos a nivel episcopal la mayoría enmarcados en su línea ortodoxa, algo que se observó claramente en Latinoamérica a la vez que otorgó una gran importancia a los movimientos eclesiales con organizaciones como el Opus Dei, los Legionarios de Cristo, Comunión y Participación o el Movimiento de Renovación Carismática entre otros de fuerte carácter tradicionalista y conservador. Si bien el Concilio Vaticano II había señalado la importancia de las Iglesias locales planteando una "eclesiología de comunión" a la vez que el papel destacado que debían desempeñar las Conferencias Episcopales y la colegialidad, en el Pontificado de Juan Pablo II esas instancias se vieron desplazadas por una centralización de la conducción y recuperación de la relevancia de la curia romana. Así el fortalecimiento de la autoridad del Pontífice emerge como un dato fundamental del período. ${ }^{21}$. Por otro lado a nivel externo el Vaticano tuvo un papel importante en los acontecimientos mundiales en su confrontación con el comunismo que culminó con un fuerte realineamiento de su política exterior ante la redefinición del poder mundial y el fin de la guerra fría. La muerte de Juan Pablo II y su reemplazo por Benedicto XVI, lejos de producir cambios en la línea que se

21 Cfr Hervé Legrand O.P (1999) “ Iglesias(s) local(es)Iglesias regionales o particulares,Iglesia católica,Dossier de hechos y reflexión sistemática-pag. 162- en J.Scannone, ,T. Mifsud,H. Légrand,M.Gonzalez.G. Farrell,J.Soneira- Iglesia Universal ,Iglesias particulares- Edit. San Pablo - Bs. As. 
había desarrollado hasta ese momento implicó claramente su ratificación y consolidación. Nos encontramos entonces con un Papa con un estilo distinto al de su predecesor pero que brindó continuidad a su línea conservadora y se preocupó especialmente por diseñar "una nueva modernidad católica para el siglo XXI"22 . De esta manera, frente a las demandas de mujeres y hombres insertos en una modernidad contemporánea atravesada por nuevas tramas de sentido y movimientos de búsqueda de ampliación de derechos y procesos de autonomización, la Iglesia siguió reafirmando su ortodoxia doctrinaria y su resistencia frente a lo que consideraba como los malestares del relativismo posmoderno. De allí entonces como señala F. Mallimaci:

"Frente a aquellos que buscan entrelazar la modernidad y el cristianismo, que proclaman "una Iglesia que escuche antes de hablar" que cambie normas y formas, Benedicto XVI asume una integralidad que proclama “ Restituir la ciudadanía plena a la fe cristiana". ${ }^{23}$

Sin embargo el 11 de febrero del 2013 Benedicto XVI sorprendió a los católicos y al mundo anunciando su renuncia al papado. Un hecho que se concretó poco después y que lo constituyó en Papa emérito. Luego de 600 años un papa presentaba su renuncia a su cargo .Pero no solo resultaba sorpresiva la decisión de renuncia después de varios siglos, sino que a su vez contrastaba abiertamente con su antecesor, Juan Pablo II para quien la continuidad en su cargo, a pesar de la edad y la enfermedad, era un compromiso y un testimonio irrenunciable de lo sagrado de su cargo. Se manifiestan así una diversidad de apreciaciones desde los que consideran que la renuncia es algo que aunque inesperado esta enmarcado en la legislación canónica existente de la Iglesia, hasta los que explicitan su desconcierto e incluso reprobación ante las palabras inesperadas de renuncia. Planteos que aluden a la "debilidad" de un Pontífice acuciado por la envergadura de los problemas, pero por otro lado la opinión de quienes enfatizan el carácter moderno de la decisión considerando que la misma poseía una profunda densidad significativa más allá de la rígida trama canónica. Asimismo, en lo que respecta a las causas aparece con mayor claridad un cuadro de situación claramente preocupante, con multiplicidad de conflictos y especialmente con una crisis de enorme profundidad. Como señalamos en un trabajo anterior

"Su renuncia no aparece enmarcada en un proceso lógico de recambio sino en una situación de excepción en el marco de la cual el mismo Papa hizo manifiesta la gravedad de la crisis...". ${ }^{24}$

\footnotetext{
22 F. Mallimaci- La nueva modernidad católica de Benedicto XVI. " Auténtica fé y razón Le monde diplomatique-El diplo-Edic. Cono Sur- No. 96-Junio 2007- Pag.4

23 F. Mallimaci- op. Cit- Pag. 5

24 A. Ameigeiras - " La Iglesia Católica, entre la gravedad de la crisis y las expectativas de cambio- Cuadernos del Pensamiento Latinoamericano -No. 1-Mayo 3013-2da. Epoca$>$ Pag. 11-12
} 
En ese contexto y luego de múltiples comentarios, especulaciones y reuniones fué elegido el cardenal Jorge Bergoglio como nuevo Papa que asumió con el nombre de Francisco. Un cardenal Latinoamericano por primera vez en la historia de la Iglesia, perteneciente al continente en donde se encuentra la mayor cantidad de católicos pero también en donde más ha crecido el pentecostalismo y se incrementa la presencia de creyentes sin religión. Un continente por otro lado caracterizado por la desigualdad social y la pobreza pero en donde en los últimos años se han consolidado experiencias políticas democráticas con un fuerte protagonismo popular y con el despliegue de políticas de apertura y reconocimientos de derechos. Un Cardenal argentino identificado con la línea doctrinal de sus antecesores, conocido por su ortodoxia y conservadurismo por sus pares que participaban del cónclave, y que había obtenido una cantidad de votos muy importantes en el consistorio anterior cuando fue elegido Benedicto XVI ( en donde cedió sus votos 'para facilitar la elección)e incluso reconocido por sus pares Latinoamericanos por la actuación que había tenido en la elaboración final del documento del VI Encuentro Episcopal de Aparecida en Brasil en su rol como Arzobispo de la ciudad de Bs. As.. Pero también un cardenal que ha sido cuestionado en la Argentina, especialmente por personas y organismos vinculados a los DDHH, debido a su actuación en el caso de dos sacerdotes durante el período de la dictadura cuando era el Superior Pcial de los Jesuitas como por su oposición como Arzobispo a la ley de matrimonio igualitario y sus planteos ante algunos temas claves en discusión en la Iglesia Católica ${ }^{25} \mathrm{en}$ su desempeño en la ciudad Autónoma de Bs. As.

El nuevo Papa comenzó su papado dejando de lado símbolos de ostentación y poder fuertemente arraigados en la tradición y las ceremonias protocolares respecto a los Pontífices en el Vaticano. Por el contrario desplegó gestos de sencillez y austeridad que más allá de su repercución mediática han tenido una fuerte significación entre los creyentes católicos. Por otro lado en sus primeras alocuciones, homilías y declaraciones produjo apreciaciones que también generaron distintas expresiones de aprobación, sorpresa o cuestionamiento. Una enfatizada apelación al " pueblo de Dios", al " pueblo de los "pobres" o a la "religión del pueblo", profundizadas cuando afirmó que le gustaría tener " una Iglesia pobre para los pobres". Sin embargo, ni sus gestos ni sus palabras son totalmente novedosos para quienes lo conocían con

25 Ver al respecto : GF. Mallimaci “ Papa Francisco : Entre la modernidad católica y la recomposición religiosa”-Pag. 15- Cuadernos del Pensamiento Latinomaericano Clacso-Mayo 2013// J. Esquivel (2013) “ La carrera por un Papa propio “- Le Monde Diplomatique No. 166-Edic. Arg. //V. Gimnenez Beleveau- (2013) “ Papa Argento- Sup. SOY - Pag. 12- 15-3-2013 
anterioridad. Sus gestos ya eran conocidos por muchos de sus sacerdotes y quienes convivieron con el en Buenos Aires. Tampoco es nuevo su planteo respecto a la consideración de la iglesia y el pueblo, una afirmación que nos interesa profundizar en cuanto a partir de la misma podemos aproximarnos a un mayor conocimiento de su perspectiva teológica y pastoral. Así al hacer alusión a la "religión del pueblo "Francisco apela a una terminología enmarcada en la llamada "Escuela Argentina de Teología " ${ }^{26}$ que ha tenido en los teólogos Lucio Gera, Rafael Tello y Juan C. Scannone a sus principales representantes y que ha influenciado profundamente en el desarrollo de la Pastoral popular en la Argentina, pero también en la formación de varias generaciones de sacerdotes. Una línea surgida en un contexto vertebrado por el Concilio Vaticano II, la creación de la COEPAL (Comisión episcopal de pastoral en la Argentina) la Conferencia de Medellín, y el Manifiesto de los Obispos del Tercer mundo. Francisco se identifica con la línea de sus antecesores pero incorpora a dicha orientación diferencias expresadas en términos de una marcada orientación por lo "popular" y lo " cultural" en especial con la religión de los sectores más pobres del pueblo claramente enmarcada en la línea teológico a la que hemos aludido. Es que la "teología del pueblo" coloca un eje vertebrador en la consideración de la cultura y la religiosidad de los pueblos Latinoamericanos llevando a cabo una lectura particular de la " experiencia de ese pueblo de Dios, ponderando la religiosidad de los sectores pobres y excluidos. Una teología que se diferencia de la "teología de liberación" en relación al "tipo de mediaciones que se usarán para acceder a la realidad de los pueblos “. ${ }^{27}$ Mientras la teología del pueblo coloca el énfasis en el "análisis histórico-cultural", la teología de la liberación lo hace en el "análisis socio-estructural ",mientras la primera enfatiza la relevancia de la historia y la cultura del pueblo la segunda lo hace en la necesidad de denuncia de la "situación de injusticia" de los pobres y oprimidos. ${ }^{28}$ Resulta interesante observar sin embargo que algunos teólogos como precisamente G. Gutierrez ${ }^{29}$ consideran que más allá de las discrepancias que posee esta teología con la Teología de la Liberación ,puede ser considerada como una

26 S. Politi(1992) Teología del Pueblo-Una propuesta argentina para Latinoamérica- Edit. Guadalupe-Bs. As.

27 S. Politti -(1992) Teología del Pueblo - Edit. Guadalupe- Pag. 302// ver también J. C. Scannone - La Teologia de la Liberación ;Caracterización, corrientes .etapas.pp. 21-80 en J.Scannone - Teologia de la Liberación y Doctrina social de la Iglesia- Edic. Crtistiandad y Guadalupe- 1987-Madrid //

28 G.Gutierrez ( (1987\% “Teología de la Liberación -Perspectivas- Edic. Sígueme 7.edic. España.

29 G. Gutierrez- 1988 La fuerza histórica de los pobres-pag.317 cEP- Lima- Citado por Jc .C Scannone-op. Cit. Pag 126 
corriente teológica diferenciada de la misma.En esa perspectiva también J.C. Scannone se encarga de aclarar que más allá de que pueda o no ser considerada una corriente de dicha teología de la liberación ,la teología del pueblo ha hecho aportes importantes a la misma especialmente en lo referido a nociones como, Pueblo de Dios , Cultura y religión del pueblo. ${ }^{30}$

En esta línea teológica R. Tello es una de las figuras más destacadas en cuanto profundiza especialmente la significación de la "religión del Pueblo" considerando que la Iglesia debe encarnarse en la cultura del pueblo de manera que el catolicismo que se "encarna" en la cultura popular se constituye en una clave fundamental de la evangelización. Se trata de considerar ese cristianismo como " la matriz y la referencia de las demás formas de evangelización y de vida cristiana :la calidad del catolicismo..." Un ${ }^{3}$ planteo teológico que implica enfatizar la singularidad de la cultura y el catolicismo del pueblo pobre considerada como un" baluarte de resistencia" frente a culturas que se le quieren imponer. En esa perspectiva tanto la modernidad como la posmodernidad constituyen la expresión de una cultura ilustrada que es la expresión de una élite y se ha apartado de la tradición y cultura del pueblo pobre. ${ }^{32} \mathrm{Es}$ interesante observar a través de la trayectoria del papa Francisco, especialmente cuando aún estaba lejos de dicha investidura, la incidencia de la teología del pueblo Así en 1985 cuando presidía el Congreso Internacional de Teología pronunció un discurso inaugural en el que explicitaba entre otros aspectos;

"Lo absoluto del Evangelio encuentra allí en el corazón cultural de los pueblos,en su manera real y sabia de ordenar su vida cotidiana gustando valores trascendentes, un lugar adecuado en donde encarnarse, una tierra fecunda donde poder hacer crecer al hombre desde si mismo que es la manera de evangelizar,crear,restaurar y perfeccionar de Dios." 33

Un tipo de apreciación que reafirma unos años mas tarde en 1985 cuando llevo a cabo la Lección inaugural en el comienzo de un curso académico ;

30 J. C. Scannone - 1997- Los aportes de Lucio Gera a la Teología en perspectiva Latinoamericana- pag. 128 y 129 en .R. Ferrar - C. Galli (eds) Presente y futuro de la Teología en Argentina- Homenaje a L Gera- Edic. paulina- UCA-

31 Marcelo Gonzalez (2002) Teologia de la historia desde la perspectiva argentina-La contribución de L.Gera y RTello-Pag. 243 / Stromata No. 3/4- Facultad de Filosofia y Teologia Sa Miguel. 2002-)

32 N. Gonzalez . op. Cit. 244

33 Jorge M. Bergoglio - Discurso inaugural Congreso Internacional de Teología- “ Evangelización de la cultura e Inculturación del evangelio “ - Stromata - Julio - diciembre 1985- San Miguel - Bs. As pag. 163- 
"Si vemos al hombre posmoderno sumergido en la confusión del desengaño de su falida omnipotencia,no hallaremos otra forma de rescate que el reencuentro solidario con su pueblo, unidos por el vínculo de desear al Dios que es Principio y fin de su acción libre....Compartir la conciencia colectiva de un pueblo es dejarse acompañar con la única objetivación del bien mutuo,dejarse iluminar por la piedad con que el mismo pueblo se reubica y se deja atraer hacia el Fin que lo mueve, que lo justifica y da esperanza y le confiere la alegría de ser." 34

Asi si observamos en la actualidad, en una de sus últimas entrevistas el Papa Francisco recupera nuevamente esta noción central de volver a encontrar el evangelio en el " corazón cultural de los pueblos".

"El pueblo es sujeto y la Iglesia es el Pueblo de Dios en camino a través de la historia, con gozos y dolores. Por tanto para mi quiere decir estar en este Pueblo “ 35

Su insistencia en la relevancia de "una Iglesia pobre para los pobres " se vincula de esta manera con una apreciación teológica que demanda una conversión de una Iglesia fuertemente enmarcada en una cultura más selecta a una cultura del pueblo y especialmente del pueblo pobre. Pero por otro lado la apelación a "los pobres" constituye una expresión que posee en si misma una honda significación para la Iglesia católica en general y la Iglesia Católica Latinoamericana en particular, situación que incrementa las preguntas en torno al alcance y la significación de dichas palabras. No solo porque recuerda las palabras pronunciadas por Juan XXIII un mes antes de inaugurar las sesiones del concilio Vaticano II ${ }^{36}$ sino porque las mismas encontraron en la Conferencia y el documento de Medellín(1968)un ámbito fundamental y fecundo de asunción y profundización. Palabras que en el marco de la teología de la liberación marcaron la relevancia fundamental y vertebradora de la "opción por los pobres",pero que dió lugar también a otras lecturas teológicas. Es aquí en donde es necesario analizar en profundidad los significados que adquiere esa "Iglesia de los pobres" en ambas teologías a las que hicimos referencia. En esa línea surgen los interrogantes nuevamente ¿¿Dichas

34 Jorge M. Bergoglio - (1989) "Necesidad de una antropología política:Un problema pastoral"- Lección inaugural del curso académico 1989 en las Facultades de Filosofía y Teología de la Universidad del Salvador, área San Miguel- Rev. Stromata - No. $1 / 2$ - Enero -Junio 1989- pag 188."

35 P. A. Spataro-(Dir. Revista Civitqa Cattolica- Entrevista exclusiva- Papa Francisco: “ Busquemos ser una Iglñesia que busca caminos nuevos “- Razon y Fe- 2013- pag.10

36 Juan XXIII(1959) Radiomensaje “ Hoy la Iglesia es especialmente la Iglesia de los pobres"- 11 set- 1959)- Citado por Jon Sobrino “La Iglesia de los pobres” - Venturas y desventuras del papa Juan XXIII a Monseñor Romero - pag 115- en Concilium-Rev. Internac. De Teología- No., 349- Febrero 2013 
palabras son parte de un cambio que abre una perspectiva de transformación profunda en la manera de ser Iglesia en el marco de esta modernidad contemporánea o por el contrario se trata de un cambio representativo de una corriente teológica y pastoral pero que no se traduce en transformaciones profundas y por el contrario se articula con una continuidad ortodoxa predominante en la Iglesia. Resulta interesante lo señalado por J.- P. Martin :

"El Papa ha expresado muy bien los términos de una lucha cultural como lo había hecho la teología antimodernista pero esta vez no desde una filosofia apologética sino desde el recuerdo de las primeras exhortaciones de los predicadores del evangelio ".37

Los primeros pasos de Francisco se orientan, según sus propias declaraciones, más allá de los gestos a los que hicimos referencia, al propósito de realizar el ordenamiento y transparencia de la curia, especialmente en lo que hace a clarificar el desorden económico como en lo que respecta a algunos cambios , tal como ocurrió con el nuevo Secretario de Estado del Vaticano, Pietro Parolín y el nombramiento de una comisión de Cardenales para considerar la necesidad de reformas. Por otro lado ha avanzado en declaraciones que no han rehuído temas como el celibato de los sacerdotes, la homosexualidad y el divorcio entre otros, explicitando frente a los mismos, más que definiciones o posicionamientos frente a la temática, una actitud de "comprensión" y de convocatoria a ser " misercordioso". En la entrevista concedida al director de la revista Civilitá Cattólica fue explícito precisamente respecto a la necesidad de una actitud de " misericordia".Transita así por un camino en donde por un lado aparece un cambio de actitud y por el otro no se encuentran aún respuestas ni planteos precisas en torno a la problemática y la decisión que tomará la Iglesia en cuanto a las reformas anheladas. Asimismo también ha señalado que para realizar cambios profundos en la Iglesia se requiere tiempo.

"Son muchos, por poner un ejemplo,los que creen que los cambios y las reformas pueden llegar en un tiempo breve.Yo soy de la opinión de que se necesita tiempo para poner las bases de un cambio verdadero y eficaz." 38

Nuevamente la pregunta ¿ Estamos ante un Papa que pondrá las bases de un cambio mayor? ¿Qué tipo de reformas son las que está planteando ? Actitudes que sorprenden a muchos y prontamente los pronósticos sobre el

\footnotetext{
37 J.P.Martin (2013) Catolicismo y Papado.Historia y situación actual-UNGS- pagina 12-No., 4-9-2013-La Univ. interviene en lo debates nacionales"

38 Antonio Spataro- ( 2013) Entrevista exclusiva - Papa Francisco “ Busquemos ser una Iglesia que encuentra caminos nuevos “- Revista Razón y Fé . - pag., 5
} 
futuro Papa y la Iglesia se polarizan desde los que explicitan una cierta euforia pasando por lo que observan esperanzados hasta aquellos que por el contrario mantienen su escepticismo. Se consolidan las certezas de un lado y se profundiza la incertidumbre del otro. Se acrecienta los interrogantes respecto al camino que emprenderá la institución con la conducción del nuevo Papa. Un camino de continuidad o por el contrario de cambios. La gran pregunta pasa ser nuevamente si estaremos ante un nuevo giro institucional y en ese caso cual será la característica del mismo. Juan Pablo II desplegó una perspectiva conservadora y de centralización de la conducción, pero cultivó una relación directa y emocionalmente muy fuerte con el pueblo creyente de las distintas latitudes. Recuperaba así, en el marco de un abroquelamiento doctrinario una amplitud de contacto colectivo fuertemente emocional. Francisco se identifica con la ortodoxia de Juan Pablo II pero sustenta una apreciación teológica y pastoral que sustenta un cambio de actitud y más que un vínculo directo una nueva relación y valoración de una cultura y una religiosidad que se arraiga profundamente en la religiosidad y la cultura popular. Quizás la respuesta a la preguntas no pase solamente por la continuidad, ni tampoco por el cambio, sino precisamente por un cambio en la continuidad, un cierto giro institucional que si bien puede habilitar cambios importantes, no genera en lo inmediato transformaciones o reformas. El desarrollo de los acontecimientos nos mostrará en que medida estamos ante la antesala de un nuevo giro, un cambio de perspectiva que implica comenzar a transitar un nuevo camino tendiente a dar respuestas a las múltiples demandas existentes y a encarar una reforma profunda, o por el contrario el giro no implicará modificaciones sustantivas sino la producción de un cambio que garantizará la continuidad.

Submetido em: 19-10-2013

Aceito em: 1-11-2013

Estudos de Religião, v. 27, n. 2 • 159-176 • jul.-dez. 2013 • ISSN Impresso: 0103-801X - Eletrônico: 2176-1078 